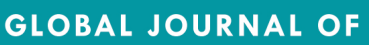 \\ Community Psychology Practice
}

Recovery: Re-establishing place and community resilience

Joseph O. Prewitt Diaz

Research Center on Psychosocial Support in Disasters

Author Notes: Requests for reprints should be sent to Joseph O. Prewitt Diaz, Research Center on Psychosocial Support in Disasters, Alexandria, Virginia 22312 jprewittdiaz@gmail.com

Keywords: recovery, place, community resilience

Recommended citation: Prewitt Diaz, J. O. (2013). Recovery: Re-establishing place and community resilience. Global Journal of Community Psychology Practice, 4(3), 1-10. Retrieved Day/Month/Year, from (http://www.gjcpp.org/). 


\section{Recovery: Re-establishing place and community resilience}

The purpose of this review is to suggest steps in the recovery process to help victims reestablish place and build community resilience via an on-going, adaptive resilience assessment. The methodology consists of a review of the literature, case studies from recent disasters in the United States, and the authors' prior experiences. The article demonstrates place and adaptive resilience as two integrated concepts that represent the desire of disasteraffected people to achieve their recovery.

Keywords: recovery, place, community resilience

\section{Introduction}

As a result of major disasters in the US and around the world during the last decade, public and private (e.g., governmental, faith-based, and local) community agencies have attempted to formulate parallel structures to improve community resilience in the event of future disasters. Recent research (Connor, 2006; Cutter et al., 2008; Scannell \& Gifford, 2010) has suggested that disaster-affected people rely on place attachment to promote the reconstruction of their homes and neighborhoods. As they move forward, psychosocial support activities assist the victims in their efforts to identify bonds with their place and develop adaptive resilience. Adaptive resilience is the capacity to stay active and moving forward toward improvement of the situation in spite of constant changes in the environment. Ultimately, these activities contribute to alleviating suffering and enhancing resilience, thereby supporting the affected community members' ability to face the future and improve wellbeing.

This paper suggests steps in the recovery process that can help victims re-establish place and build community resilience via an on-going, adaptive resilience assessment. To accomplish this goal, this paper provides a review of existing literature and a description of some examples from my personal experiences after my active participation in the recovery efforts associated with low impact disasters (e.g., the Northridge Earthquake, the $2001 \mathrm{El}$ Salvador earthquakes, and the 2001 Gujarat Earthquake in India), moderate impact disasters (e.g., Hurricane Andrew in Puerto Rico and several floods in Ohio and West Virginia), and high impact disaster (e.g., the 1998 Las Casitas landslides in Nicaragua, the bombing of the Murrah Federal Building in Oklahoma City, the 9/11 terrorists attacks, and the 2004 Southeast Asia tsunami).

At the advent of the $21^{\text {st }}$ century, disaster responders faced major challenges in their attempts to assist the survivors of major disasters (e.g., 2001 Gujarat Earthquake, 2003 Bam Earthquake, 2004 Southeast Asia Tsunami, 2005 Hurricane Katrina, and 2005 Pakistan Earthquake). Indeed, disaster-related mental health and psychosocial support needs were not considered traditional disaster response methods at that time; instead, traditional disaster response mainly focused on attending to basic needs. Yet, massive disasters often involve dislocations, large numbers of casualties, and widespread human suffering, all of which can hinder the recovery process of disasteraffected people. This is quite concerning considering the fact that the traditional disaster response methods that were the sole focus at the beginning of this century are not designed to help victims psychologically heal from these catastrophes.

Spearheaded by the Interagency Standing Committee (IASC, i.e., a representative group based in Geneva with representatives from United Nations [UN] agencies, the Red Cross, and other nongovernmental organizations [NGOs]), a group of concerned agencies began to explore the possibility of protecting the mental health of disaster-affected persons while addressing their psychosocial needs. In 2007, this group published guidelines to encourage humanitarian workers to become increasingly active in the protection and improvement of survivors' mental health and psychosocial wellbeing in the aftermath of disasters (See IASC, 2010). These guidelines provided an overview of essential knowledge about mental health and psychosocial support (MHPSS) in humanitarian emergencies. By using the term psychosocial, the IASC recognized the interconnection between psychological and social processes and the continual interaction and influence between the two in the recovery of disaster-affected people (IASC, 2010, p. 1).

In 2008, the North Atlantic Treaty Organization (NATO) proposed guidelines for the psychosocial care of disaster-affected people. Ultimately, these guidelines acknowledged that the means by which psychosocial responses to disasters are managed may be the defining factor that determines a community's ability to recover. The restoration of the psychosocial fabric of communities and the protection of vulnerable people are important components of the facilitation of recovery (NATO, 2008: pp. 1-8 and 19).

Moreover, the 2011 Sphere Handbook, which contains standards for humanitarian responses, was modified to include psychosocial support as an allencompassing issue. Furthermore, this handbook 
indicated that community self-help and social support are essential to the efforts to increase self-help and social support. Additionally, this handbook indicated that community workers and volunteers who can support community members and provide psychological first aid when needed must be included in the efforts to provide psychosocial support (Sphere Handbook, 2011, pp. 334-335).

In the US, the Homeland Security Administration and its lead disaster agency, i.e., the Federal Emergency Management Agency (FEMA), have provided guidance through their Emergency Support Functions (ESFs) (FEMA 2008, 2010, 2011), which are based on lessons learned from Hurricane Katrina, the 9/11 terrorist attacks, and Super Storm Sandy, 2012) As evidenced by these documents, Homeland Security and FEMA have begun to identify strategies to foster the enhancement of community resilience and wellbeing in affected communities. Yet, these approaches have not offered ways in which community assessment tools may open spaces and opportunities for disaster-affected people to gain an understanding of their place (i.e., what they had); the physical, ecological, and psychological loss resulting from the disaster; and the tools that they have at hand to move forward in the process to re-establish and recover their place, enhance resilience, and promote wellbeing.

\section{Natural disasters - Causing destruction of place}

Major disasters instantly fracture social and psychological community networks. For example, this was clearly evidenced by the displacement and relocation of thousands after the Oklahoma tornadoes in early May of 2013. When physical, social, or psychological place is destroyed, disaster-affected people grieve their place in ways similar to mourning a death. The loss of access to places of cultural and social significance and the resulting loss of connection to other affected people undermine a community's ability to act, thereby exacerbating the grief. Disaster-affected people often feel out of control and experience helplessness and vulnerability. Trauma can cause people to see the world as threatening, which causes some to be drawn together in groups to help re-establish boundaries and structures, thereby creating a new sense of place. Others feel estranged and want to be alone. Traumatic events can either mobilize and strengthen or fracture a family, group, or a community (Fullilove, 1996; Norris, 2002).

Even when the individual reacts in a productive manner to the situation, a disaster typically disrupts and destroys lifestyles, places, and feelings of safety. Disasters, both natural and man-made, have common effects; i.e., they produce trauma that changes the social and emotional lives of individuals, the resilience of families, and the cultural fabric of communities. These non-routine events cause considerable harm to the physical, social, and psychological environment. They occur across a defined time and place and can contribute to the collapse of individual and communal bases; moreover, they start a chain of events that triggers further events and responses, all of which may last several years (Norris, 2002).

During a large-scale disaster, such as Hurricane Sandy, the combined effects of the displacement of large numbers of people, the damage to the natural environment, and the destruction of the built environment can destroy the place and spirit of the people who have been deeply impacted. Moreover, the reliability of social networks and the reliability of community support systems (e.g., the fire department, health facilities, and shelters) is almost always disrupted by such disasters (Cutter et al., 2008).

\section{Significance of place}

Place is functionally defined as a collection of meanings, beliefs, symbols, values, and feelings that individuals or groups associate with a specific locality (Williams \& Stewart, 1998). A disruption of place impairs an individual's ability to integrate their past with their present life due to the lack of tangible social and environmental cues and symbols. This disruption of place may be manifested in the fracture of emotional bonds that people form over time; the loss of strongly held values, meanings, and symbols; the loss of the quality of place, which may be taken for granted until it is threatened or lost; the loss of place meanings that are actively and consciously constructed and reconstructed within the affected peoples' minds; and/or the loss of shared cultures and social practices (Fullilove, 1996).

Fullilove (1996) defined "place" as a setting where disaster-affected people feel that they have a good enough living environment. The perception of disaster-affected people is linked to the surrounding environment through the following three key psychological processes: attachment, familiarity, and identity. Place attachment involves a mutual caretaking bond between a person and a beloved place. Familiarity refers to the processes by which people develop detailed cognitive knowledge of their environs. Place identity is concerned with the extraction of a sense of self based on the places in which an individual spends his/her life. Each of these psychological processes (i.e., attachment, familiarity, and place identity) can be threatened by

displacement; consequently problems associated with nostalgia, disorientation, and alienation may ensue (Fullilove, 1996, p. 1516).

In contrast, Stedman (2002) studied the symbolic meaning of a place. The data from his study revealed the importance of symbolic meanings as an underpinning for the conceptualization of place satisfaction as an attitude toward a setting and the 
conceptualization of attachment as personal identification with a setting. In turn, attachment, satisfaction, and meaning all have independent effects on the willingness to engage in behaviors that maintain or enhance the valued attributes of the setting, i.e., adaptive resilience (Cutter et al., 2008).

Loss of place taxes the physical, social, and psychological wellbeing of disaster-affected people. Shalev and Ursano (2003) indicated that physical needs, e.g., hunger, pain, or dehydration, can cause disaster-affected people to feel insecure and apprehensive about their future. Loss of familiarity with pre-disaster social networks, community structures, and financial and personal resources (Davis, Grills-Tequechel, \& Ollendick, 2010) disrupts social, communal, and regular daily living and generates distress. In fact, relocation is an assault to the territorial habits of humans. Indeed, this forced separation uproots people from their cherished land, familiar environments, precious objects, and reassurances of life. Uncertainty related to the source, force, and duration of a disaster can cause extreme distress, thereby feeding feelings of separation, disconnection, and detachment and the inability to resonate with others (McFarlane \& Williams, 2012; Norris, 2002; Shalev \& Ursano, 2003). Clearly, programs aimed at helping disaster-affected people to overcome these problems associated with the disaster and loss of place would be beneficial.

\section{Psychosocial support and adaptive resilience}

Psychosocial support programs involve communitybased activities that enhance adaptive resilience and improve community-wide wellbeing (IASC/MHPSS, 2007; SPHERE, 2011). Once the initial phase of the disaster response has established some stabilization amongst the disaster-affected people, the response program should engage them in actively exploring their place, where they have been, and what they need to do in the future. The conversations that emerge in this process serve as a therapeutic tool that brings people together, gives them space to share their stories, and permits the development of a road map to re-establish place and enhance resilience. However, note that the psychosocial needs of disaster-affected people vary. Therefore, a critical step toward recovery is to determine the needs related to protective factors offered by the community, which can be delineated into the following three major areas: assets of the affected community, symptoms versus disaster/conflict generated problems, and the extent of stakeholder engagement.

Psychosocial assessment is a part of any psychosocial support program and involves a process of collecting, organizing, and analyzing information about a community. An adaptive resilience approach to psychosocial assessment helps build an understanding of a community's vulnerabilities, resources, and adaptive capacities, all of which drive its response to change. In psychosocial support programs, the primary intervention focuses on getting disaster-affected people to communicate (e.g., individually or in small groups, such as focus or interest groups, or in larger community representative groups). This process is the foundation for psychosocial assessments. More specifically, information is systematically collected to create an overview of the history, livelihood, mores, and cultural nuances of the community. Key informants and local leaders often emerge through this process and engage in conversations with formally appointed leaders, elected officials, and faith-based leaders.

Maguire and Cartwright (2008) indicated that the process of adaptive resilience identifies the resources and adaptive capacity available to a community to overcome the problems that may result from change and works to build upon the inherent capacities of a community rather than only relying on external interventions to overcome vulnerabilities. This approach accepts that change is inevitable and unpredictable. Rather than relying on external sources of strength and action to overcome issues, the resilience approach builds upon the capacities (e.g., resources and flexibility) that have already been established within a community.

The resilience approach is balanced in that it includes both the vulnerabilities within a community (i.e., versus labeling an entire community as vulnerable) and the resources and adaptive capacities that enable the community to overcome these vulnerabilities and manage change in a positive way. A resilience perspective fosters an adaptive form of governance, which encourages the sustainable use of environmental and social resources (Folke, 2006).

Moreover, a resilience based psychosocial assessment recognizes the inherent complexities and interactions between a community's resilience, vulnerability, and adaptive capacity (WHO, 2012). Furthermore, such an assessment also considers the fact that community perceptions vary according to the stage of recovery after a disaster.

This type of approach generates richer and more useful data (Cutter et al., 2008). Moreover, an adaptive resilience perspective is able to capture the complexity that is inherent in human-environment systems and the social changes within those systems instead of attempting to control change ("Listening to Joplin-Next Steps," 2012). Additionally, the adaptive resilience perspective recognizes that change and uncertainty are inevitable and that communities are dynamic. For example, in the case of the recovery from catastrophic tornadoes in Joplin, $\mathrm{MO}$, the compilation of community ideas from affected and unaffected residents recognized change and the dynamism of the community in recovery. Additionally, as previously implied, the adaptive resilience perspective allows for the assessment of 
resources and adaptive capacities within a community, not just its vulnerabilities. For example, the citizens of Joplin decided to "carve out an enclave to provide a respite from the complications and overstimulation of life" in recognition of their resilience ("Listening to Joplin Report," 2011). The collective activities of disaster-affected people and the surrounding community can point to the protective factors and social capital through which disaster-affected people can re-establish their physical, human, and psychosocial place.

An example of this approach was evident in a community meeting held in Joplin in the aftermath of the tornadoes that destroyed that small city on May $22^{\text {nd }}, 2011$. The tornado caused extensive damage and 161 deaths. In a blog dated October $26^{\text {th }}, 2012$, the blogger reported the following steps on the road to recovery in Joplin:

- Formation of a Citizens Advisory Recovery Team to ensure all segments of the community were engaged in recovery conversations, sharing ideas, exchanging information, and working collaboratively;

- Development of a community recovery vision and supporting goals; and

- Compilation of all ideas in a booklet to be shared widely amongst internal and external stakeholders.

\section{Recovery through psychosocial support}

Long-term recovery programs must include the participation of disaster-affected persons who have been displaced as a result of the disaster (Sphere Project, 2011). These programs include psychosocial activities designed to re-establish place attachment. Ultimately, psychosocial support is best defined as interventions that help disaster-affected people in the resumption of normal life by actively engaging in their recovery, thus promoting adjustment and resilience. Oftentimes, these psychosocial activities focus on providing safe, secure spaces in the form of small group meetings where disaster-affected people can share memories of their place, what happened to their place, the consequence to them, and activities that will lead to the re-establishment of place. In such gatherings, small self-selected groups of disasterdisplaced people meet and begin the process of bonding with each other and their place. The common objective is to share an understanding of place attachment, place identity, ancestral ties, and the desire to return to their former place.

The groups may begin to reflect and share their feelings of sadness and longing, feelings of love and pride, and how they define wellbeing in their place (Brown, Perkins, \& Brown, 2003; Fullilove, 1994; Relph, 1976; Scannell \& Gifford, 2010). The second purpose of these small group meetings is to identify human resources, material resources, and common priorities in all sectors within the community. Discussions within these smaller groups would probably focus on the following five areas:1) emotional support, 2) sharing information and affirming the value of family members and what they do, 3) sharing information about members belonging to a larger group for whom they have a responsibility and from which they can get something in return, 4) sharing information on evaluation to give members a sense of boundaries, and 5) sharing information indicating the importance of self-sacrifice for the benefit of others as a means of enhancing self-esteem and worth (McCubbin, McCubbin, Thompson, Han, \& Allen, 1997).

\section{Core activities in psychosocial support programs}

Psychological first aid is a valuable tool used in the psychosocial support activities to facilitate adaptive resilience. Through the use of psychological first aid, friends, relatives, peers, churches, community groups, and external stakeholders usually provide support that enhances security and calmness while promoting active engagement in re-establishing place (Sphere, 2011; Hobfoll et al., 2007).Connor (2006) found that individuals use positive emotions to recover from negative emotional experiences; therefore, psychological first aid should focus on generating positive emotions. Moreover, the evaluation of resilience should focus on strengths and positive attributes, thus encouraging individuals to undertake more adaptive activities. Ultimately, this will facilitate and enhance the capacity of all segments of the community to work together to identify their place attachment needs and define activities that will ameliorate the disaster-related condition of their place. The policies of FEMA and other governmental entities that exert influence at the community level must integrate adaptive resilience into discussions on re-establishment of the natural and built environments (Cutter et al., 2008).

The changes that occur within disaster-affected people as a result of their displacement and exploration of place attachment may actually serve to strengthen key relationships and systems that support spiritual, psychological, and social wellbeing. The identification of these positive forces is equally important in the effort to highlight processes that support adaptive resilience. However, disasterinitiated person-place bonds decrease with increased mobility. Moreover, disaster-related environmental problems ultimately threaten connection to place (e.g., beach erosion, such as the impact of the surge in the Rockaways, NY) (Sanders, Bowie, \& Bowie, 2003; Scannell \& Gifford, 2010). Nevertheless, the provision of training for local personnel and provision of space for psychosocial support activities to promote the capacity of disaster-affected people to increase psychosocial harmony and satisfaction often results in collaboration among the local personnel and disaster-affected people despite varying historical 
experiences, values, and symbols (Scannell \& Gifford, 2010).

Exploration of the importance of the social and physical place is also essential (Scannell \& Gifford, 2010). People are usually attached to places that facilitate social, psychological, cultural, and spiritual relationships and foster group identity. For example, the Rockaways in New York City is home to many firemen and policemen; moreover, the local population is predominantly Irish Catholic. Therefore, part of identifying this area as home for these people is the connections they share with their neighbors in terms of employment and religion. Psychosocial support activities should explore ties related to place, such as the neighborhood, barber or beauty shop, corner store, clubs, churches, or parks, while also considering the way that the residents' common background plays into these ties.

Coping strategies directed at diffusing stress often lead individuals to seek support from others.

Decreased emotional or psychological distress improves psychosocial adaptation and increases higher subjective perceptions of wellbeing. Cairney, Boyle, Offord, and Racine (2003) suggested that disaster-affected people should contribute to the process to build social support networks used to meet their needs and the needs of their families. Involving individuals, families, and organizations in the development and maintenance of social support networks in the community is essential to the social cohesion of place and to the spiritual and psychosocial wellbeing of individuals and groups.

Psychosocial activities provide the opportunity for disaster-affected people to use their social capital, i.e., to explore social networks and to transform themselves based on personal resources. Social capital has been described as the density of civic associations and the levels of trust, norms, and sanctions within a given community (Fine, 2001). Social capital is related to place dependence. Place dependence implies that disaster-affected people know and can organize the details and features of their environment (Fullilove, 1996). Disaster-affected people have an absorptive capacity, defiened as the ability tor ecognzie the value of new information, assimilate it, and apply it. This includes ecological, psychosocial, and built capital attributes. The absorptive capacity of disaster-affected people includes various adaptive behaviors, such as individual psychosocial characteristics, the ability to interact and engage with other disaster-affected people and outsiders, economic activity within a society, interaction with the natural environment, and the capacity to modify said environment. Moreover, natural ecological features within a given place, such as forests, rivers, creeks, and open fields, provide health and wellbeing.

\section{Psychosocial support activities that foster place attachment}

Scannell and Gifford (2010) define place attachment as a bond between an individual or group and a place. This bond can vary in terms of the spatial level, degree of specificity, and social and physical features of the place, and it is manifested through psychosocial processes. Based on this definition, psychosocial support activities that foster place attachment can include:

1. Enhancing the survivors' capacity to prepare their own place development plan with strategies for implementation;

2. Increasing the information base by mapping the place to consider natural systems, the built environment, and psychosocial systems in the area while identifying the available social and environmental capital;

3. Facilitating the community's decision making capacity by encouraging participation of all community segments;

4. Enhancing negotiations and conflict resolution capacities for all disaster-affected people involved in the process;

5. Facilitating involvement of other outside agencies or groups as needed to improve the psychosocial, cultural, ecological, economic, and legal environment in the target place within the larger community; and

6. Designing and executing adaptive resilience projects.

Planning adaptive resilience projects is a "futuristic activity," i.e., proactive and collaborative rather than reactive and sequential. The planning of these activities must include the details of timing, budget, and phasing. Unfortunately, the surrounding chaos, suffering, and time pressures often associated with emergency settings push federal, state, and local agencies; NGOs;faith-based organizations; and small community development programs to act quickly without taking time to learn about local beliefs and practices. Consequently, many important opportunities to help disaster-affected people are lost while canned, culturally inappropriate programming may be imposed by outsiders (Berke \& Campanella, 2006). Indeed, the meaningful participation of disaster-affected people in the assessment, planning, and implementation stages of an adaptive resilience project are essential for the generation of appropriate activities, a sense of ownership amongst the disasteraffected population, and the increased likelihood of sustainability.

\section{Planning and implementing culturally appropriate adaptive resilience projects}

Proper planning and implementation of adaptive resilience projects can enhance the psychosocial competence of disaster-affected communities. Good resilience projects involve a cycle where the 
community assesses, formulates, and evaluates the participatory interventions. Moreover, these projects use cycles of response to ultimately recognize community resources and establish a "sense of place" for the survivors. As the community takes responsibility for identifying their own needs (i.e., by seeking indigenous solutions and engaging in solution-focused activities), the recovery and the achievement of adaptive resilience improves. The assumption for these projects is that "if the absorptive capacity is exceeded and the adaptive resilience process occurs, the disaster-affected people may be more likely to achieve a higher degree of recovery" (Cutter et al., 2008, p. 603).

To ensure that programming is inclusive, contextual, culturally sensitive, and appropriate, the following four key questions should be considered when planning action steps for disaster-affected people:

What do we want? The situation analysis should identify and define the specific characteristics and problems associated with a particular category of people. Information collected from the community members for situation analysis and "problem definition" should be valid, reliable, and comprehensive. This qualitative and quantitative assessment technique identifies the response mechanism for the community resources and determines risks. The assessment process involves the whole community in the decision making process and encourages community members to take responsibility for any facility or service that may be installed in the future. Community assessment sets the stage for the adaptive resilience project. Before developing psychosocial support program activities, implementers and beneficiaries should define clear goals.

What do we have? Knowledge about the capacity of the disaster-affected people and their resources, strengths, and liabilities is crucial. An analysis of such capacities provides insight into the community's actual needs and resources, not their perceived needs and resources.

How do we use what we have to get what we want? After identifying the resources they have (e.g., manpower, tools, land, and built capital), disaster-affected people should use a participatory process to assess the utilization of these resources to achieve the desired results. The outcome of the assessment acts as a baseline for problem identification and measuring progress and is thus an element of community-based monitoring and evaluation.

What will happen when we act? The outcomes of the efforts are compared with the adaptive resilience project objectives (i.e., achieved or not). At the end of the psychosocial support activities, disaster-affected people learn that the conditions involved in developing an adaptive resilience project are dynamic, and the assessment of change will rely on spatial, social, and temporal scales. Both the degree of recovery and the potential knowledge gained from the adaptive resilience exercise influence the state of the social, natural, and built environment (Cutter et al., 2008).

The planning and development of any adaptive resilience project should follow a basic outline. Table 1 describes the basic steps that should be taken in the implementation of such programs.

Table 1: Steps to be taken when developing an adaptive resilience project

\begin{tabular}{|c|c|}
\hline Step & Results \\
\hline $\begin{array}{l}\text { Community mapping and } \\
\text { analysis of potential problems }\end{array}$ & $\begin{array}{l}\text { A geographical delineation of the place, a better understanding of the problems, and an } \\
\text { initiation for dialogue to strengthen affective bonds }\end{array}$ \\
\hline Define goals & $\begin{array}{l}\text { Clarity about what the disaster-affected people want to achieve for physical, social, and } \\
\text { psychological improvement }\end{array}$ \\
\hline Define objectives & $\begin{array}{l}\text { Community members prepare a plan focused on the activities that the disaster-affected } \\
\text { people want to develop }\end{array}$ \\
\hline Define activities & $\begin{array}{l}\text { The disaster-affected people define who will work, the materials needed, the physical } \\
\text { and financial resources available, and what resources are needed from external stake } \\
\text { holders }\end{array}$ \\
\hline Identify people responsible & Diverse members participate in various projects and responsibilities are clearly defined \\
\hline Resources & $\begin{array}{l}\text { Social capital is identified and engaged and the human resources to be developed in the } \\
\text { project development process are identified }\end{array}$ \\
\hline Establish time lines & The timeframe during which the tasks/activities will be completed is identified \\
\hline Follow-up & $\begin{array}{l}\text { Assessment to ensure that all the specific tasks/activities are completed effectively and } \\
\text { that the participants feel that they have made active contributions in order to assure a } \\
\text { sense of ownership }\end{array}$ \\
\hline Evaluation & $\begin{array}{l}\text { Verify the activities and share with others (i.e., both internal and external stakeholders) } \\
\text { what the disaster-affected people have achieved }\end{array}$ \\
\hline
\end{tabular}


Ultimately, developing a strategy involves determining the inputs that are needed to implement the project, defining the responsibilities of different groups or individuals, and specifying the roles filled by these groups and individuals in the project. Moreover, a mechanism designed to measure the progress and feedback for activities should be developed. This may involve participatory assessment meetings in which the monitoring of data and further action plans are discussed.

The completion of the resilience project must include celebrations with the participants, the community, and the supporting external stakeholders. The implementation and organization of community celebrations are hard work but important and vital parts of the mobilization. For the community, a celebration is an exciting break from the monotony of moving back from temporary housing and rebuilding. Various modes of entertainment should be included in every celebration to show pride and wellbeing. The celebration is a turning point for the community to help them recognize that they have been victorious in accomplishing their project. This single step is significant in terms of the official recognition of the community's adaptive resilience; the return of disaster-affected people to place; and the improvement in the quality of life, health, and wellness. Moreover, it facilitates an open dialogue and efforts to resolve any potential issues that may arise in the development and re-establishment of place.

\section{Case Study: Psychosocial support activities lead to adaptive resilience}

In the aftermath of the 2001 El Salvador earthquake, the country was devastated, and multiple aftershocks impacted the psychosocial wellbeing of hundreds of thousands of disaster-affected people. A group of Red Cross volunteers was sent to the affected communities to conduct assessments. Their task was to provide the space for affected people to initiate a dialogue and develop maps of the damaged structures, natural places, schools, churches, and community hangouts. The community was able to identify those who were emotionally affected in each household and suggest appropriate community-based activities. In one week, these small groups of volunteers had organized more than 120 places (i.e., neighborhoods), identified needed information, and facilitated a basic work plan developed by the disaster-affected people themselves with financial assistance of external stakeholders. Moreover, based on these actions, the community members provided input for the funding process, and the community ultimately achieved its desired objectives.

\section{Conclusion}

This review defined the nature of place and established that disasters tend to disrupt individual lives and the capacity of disaster-affected people to negotiate ways to re-establish place. The paper proposed that psychosocial support activities can be used to promote adaptive resilience; in turn, the disaster displaced persons could return to their original place or establish a new place and reestablish a sense of survival, security, support, and temporal or permanent continuity in their postdisaster lives. Behavioral bonds established in the recovery process bring people together in places that supply necessities (e.g., food, water, shelter, and other resources). Place permanency can be considered psychosocial or physical depending on the age, professional background, and interest of the people involved. Place attachment keeps disasteraffected people focused on the goal of establishing place and enhancing their resilience.

\section{References}

Berke, P. R., \& Campanella, T. J. (2006). Planning for post disaster resiliency. The Annals, 604(1), 192-207.

Breckling, B., Müller, F., Reuter, H., Hölker, F., \& Fränzle, O. (2005). Emergent properties in individual-based ecological models: Introducing case studies in an ecosystem research context. Ecological Modeling, 186(4), 376-388.

Brown, B., Perkings, D. D., \& Brown, G. (2003). Place attachment in revitalizing neighborhoods: Individual and block levels of analysis. Journal of Environmental Psychology, 23, 259-271.

Cairney, J., Boyle, M., Offord, D. R., \& Racine, Y. (2003). Stress, social support and depression in single and married mothers. Social Psychiatry and Psychiatric Epidemiology, 38, 442- 449.

Calhoun, L. G., \& Tedeschi, R. G. (Eds.). (2006). Handbook of posttraumatic growth: Research and practice. Mahwah, NJ: Erlbaum.

Connor, K. M. (2006). Assessment of resilience in the aftermath of trauma. Journal of Clinical Psychiatry, 67 (2), 46-49.

Cutter, S. L, Barnes, L., Berry, M., Burton, C., Evans, E., Tate, E., \& Webb, J. (2008). A placebased model for understanding community resilience to natural disasters. Global Environmental Change, 18(4), 598-606.

Davis, T. E., Grills-Tequechel, A., \& Ollendick, T. H. (2010). The psychological impact from Hurricane Katrina: Effects of displacement and trauma exposure on university students. Behavioral Therapy, 41(3), 340-349.

Federal Emergency Management Agency. (2008). National response framework. Washington, DC: FEMA and the Department of Homeland Security. 
Federal Emergency Management Agency. (2011).A whole community approach to emergency management: Principles, themes, and pathways for action. Washington, D.C.: FEMA and the Department of Homeland Security.

Federal Emergency Management Agency. (2012). Community resilience innovation challenges. Washington, D.C.: FEMA and the Department of Homeland Security.

Fine, B. (2001). Social Capital versus social theory: Political economy and social science at the turn of the millennium. London: Routledge Press.

Folke, C.(2006). A resilience perspective enables an adaptive form of governance, which encourages the use of environmental and social resources in a sustainable way. Global Environmental Change, 16, 253-267.

Fullilove, M. T. (1996). Psychiatric implications of displacement: Contributions from the psychology of place. American Journal of Psychiatry, 153, 1516-1523.

Hobfoll, S. E., Watson, P., Bell, C. C., Bryant, R. A., Brymer, M. J., Friedman, M. J.,... Ursano, R. J. (2007). Five essential elements of immediate and mid-term mass trauma intervention: Empirical Evidence. Psychiatry, 70(4), 283-315.

Inter-Agency Standing Committee. (2007). IASC guidelines on mental and psychosocial support in emergency settings. Geneva, Switzerland: IASC.

Inter-Agency Standing Committee. (2010). Mental health and psychosocial support in humanitarian emergencies: What should humanitarian health actors know? Geneva, Switzerland: IASC.

Maguire, B., \& Cartwright, S. (2008). Assessing a community's capacity to manage change: A resilience approach to social assessment. Retrieved from http://adl.brs.gov.au/brsShop/data/dewha_resilie nce_sa_report_final_4.pdf

McCubbin, H. I., McCubbin, M. A., Thompson, A. I., Han, S. Y., \& Allen, C. T. (1997). Families under stress: What makes them resilient? American Association of Family and Consumer Sciences Commemorative Lecture, June 22, Washington D.C. Retrieved from http://www.cyfernet.extension.umn.edu/research/ resilient.html

McFarlane, A. C., \& Williams, R. (2012). Mental health services required after disasters: Learning from the lasting effects of disasters. Depression Research and Treatment, 12. doi: 10.1155/2012/970194.
McIntyre, A. (2007). Participatory Action Research. New York: Sage Publications.

Minkler, M., Garcia, A. P., Rubin, V., \& Wallerstein, N. (2012). Community-based participatory research: A strategy for building healthy communities and promoting health through policy change. Berkeley, California: School of Public Health, University of California, Berkeley. Retrieved from www.policylink.org

Norris, F. H. (2002). Disasters in urban context. Journal of Urban Health, 79(3), 308-314.

North Atlantic Treaty Organization. (2008). Psychosocial care for people affected by disasters and major incidents. Brussels, Belgium: NATO.

Relph, E. (2008). Place and placeness. London, England: Pion Publishers.

Sanders, S., Bowie, S. L., \& Bowie, Y. D. (2003). Lessons learned on forced relocation of older adults: The impact of Hurricane Andrew on health, mental health, and social support of public housing residents. Journal of Gerontological Social Work, 40, 23-35.

Scannell, L., \& Gifford, R. (2010). Defining place attachment: A tripartite organizing framework. Journal of Environmental Psychology, 30, 1-10.

Shalev, A. Y., \& Ursano, R. J. (2003). Mapping the multidimensional picture of acute response to traumatic stress. In U. Schneider (Ed). Early Intervention for Psychological Trauma. Oxford, England: Oxford University Press

Sphere Project. (2011). Humanitarian charter and minimum standards in disaster response. Geneva: The Sphere Project. Retrieved from http://www.sphereproject.org.

Stedman, R.C. (2002).Toward a social psychology of place: Predicting behavior from place-based cognitions, attitude, and identity Environment and Behavior, 34(5), 561-581.

Turner, R. (2012). The Turner report (Blog). Joplin, MO. Retrieved from http://rturner229.blogspot.com/2011_08_01_arch ive.html

Williams, D. R., \& Steward, S. L. (1998). Sense of place. Journal of Forestry, 98, 18-23.

World Health Organization \& United Nations High Commissioner for Refugees. (2012). Assessing mental health and psychosocial needs and resources: Toolkit for humanitarian settings. Geneva: WHO. 